\title{
Bone grafting for alveolar ridge reconstruction. Review of 166 cases.
}

\section{Enxerto ósseo para reconstrução óssea alveolar. Revisão de 166 casos.}

Fued Samir Salmen"; Marina Reis Oliveira”; Marisa Aparecida Cabrini Gabrielli; Ana Cláudia Gabrielli Piveta'; Valfrido Antonio Pereira Filho'; Mario Francisco Real Gabrielli ${ }^{1}$.

\begin{abstract}
A B S T R A C T
Objective: to investigate the predictive factors of failure in bone grafts for alveolar ridge augmentation and implant surgery. Methods: we reviewed the charts of 166 patients operated between 1995 and 2014. A total of 248 grafting procedures were performed. We submitted the data to the binomial test at 5\% significance. Results: grafts to gain width of the alveolar ridge (65.32\%) were more frequent than sinus lifting $(p<0.0001)$ and the number of grafts to the posterior maxilla $(48.8 \%)$ was greater than in other regions $(p<0.01) ; 6.04 \%$ of the grafts were lost. The losses in anterior $(p<0.0309)$ and posterior $(p<0.0132)$ maxilla were higher than in the mandible. There were 269 implants installed in the grafted areas, of which only $4.83 \%$ were lost. The number of implants lost (4.51\%) in areas of onlay grafts was not statistically higher than those placed after sinus lifting $(2.63 \%, p<0.2424)$. Losses were greater in the anterior $(53.85 \%)$ and posterior (38.46\%) maxilla than in the mandible $(p<0.031)$. Regarding patients' age, $76.92 \%$ of the lost grafts $(p<0.006)$ and $80 \%$ of the lost implants $(p<0.001)$ were installed in patients over 40 years. Conclusion: failure rate was higher both for grafts and dental implants in the maxilla and in patients over 40 years of age.
\end{abstract}

Keywords: Bone regeneration. Alveolar Bone Grafting. Dental Implants.

\section{INTRODUCTION}

O sseointegration is considered indispensable for the success of dental implants. However, it is a complex process with many factors interfering in the formation and maintenance of the bone tissue around the implant, such as topography and surface roughness, biocompatibility and loading conditions. ${ }^{1}$ In addition, implants installation and success require a healthy and compatible host bone bed that allows primary stability and consequently osseointegration. However, this is not always the case. Many patients have a bone tissue that has undergone posterior irradiation, osteoporosis or, more commonly, has varying degrees of bone resorption, resulting in insufficient bone volume for implant installation. ${ }^{2}$

The minimum ideal bone conditions for implant installation are $10 \mathrm{~mm}$ of bone height and $1 \mathrm{~mm}$ of bone in width on both sides of the implant. Placement of implants in areas with reduced bone quantity may be impossible or infeasible, and if performed, will cause major aesthetic and functional defects after prosthetic rehabilitation ${ }^{3}$. In this context, insufficient bone volume, in height or thickness, is the most common clinical problem in rehabilitation with dental implants and corresponds to a clear indication of bone grafting for increased bone availability ${ }^{4-6}$.

In the posterior maxilla region, the bone volume is usually limited by the vertical resorption of the alveolar bone and the pneumatization of the maxillary sinus. Thus, procedures for bone augmentation are usually required through maxillary sinus lift surgeries ${ }^{7-9}$. In addition, bone reconstructions for vertical and horizontal bone gains are not uncommon in posterior maxilla ${ }^{10}$. In other maxillomandibular regions, bone resorption after exodontias can also be accentuated, leading to significant bone loss in height and thickness, often culminating with the atrophy of the alveolar ridge ${ }^{3}$. In such situations, reconstructive bone surgeries are necessary to correct the bone deficiencies. Currently there are several options available, such as: autogenous, homogenous and xenogenous grafts, and alloplastic materials. A combination of these materials has also been described in several situations, although the autogenous bone remains the gold standard ${ }^{4,11,12}$.

1 - Araraquara Dental School, São Paulo State University (UNESP), Oral and Maxillofacial Surgery, Department of Diagnosis and Surgery, Araraquara, Sao Paulo State, Brazil. 
Even in the case of predictable procedures with documented long-term success, complications and failures have been reported after implant surgeries. Implant loss may involve several factors, such as early loading, surgeon experience, implants inserted in areas of poor bone quality, smoking or other systemic compromise, inadequate surgical technique, among other factors ${ }^{13,14}$. In this context, in the search of the best results with implant-supported rehabilitation, it is of great interest to establish the factors that lead to graft and implant failures ${ }^{15}$. Thus, the present study aimed to retrospectively evaluate a database of 166 patients who received bone grafts and implants from 1995 to 2014, to identify and describe the predictive factors of failures in this sample.

\section{METHODS}

This study was based on a retrospective analysis, in which we reviewed the medical records of the patients treated at the Oral Face Care Clinic (Santos, SP, Brazil) who underwent graft surgeries and dental implant installation from 1995 to 2014. All inserted implants were followed for at least four months.

Patients presented partial or total edentulism with varying degrees of vertical and horizontal atrophy of the alveolar bone crest and pneumatization of the maxillary sinus that did not allow the installation of dental implants without previous reconstruction with bone grafts. We included in this study patients of both genders, regardless of age or race. We excluded systemically compromised patients with a history of radiotherapy in the head and neck region or use of chemotherapeutic agents with active periodontal disease involving the remaining dentition and with their medical records incompletely filled. Thus, we reviewed the medical records of 166 patients who met the inclusion criteria. They undergone 248 graft surgeries, between maxillary sinus lifting surgeries and onlay grafts, and installation of 269 implants.

All reconstructive onlay surgeries were performed with autogenous bone of the mandibular retromolar area, and the maxillary sinus lifting procedures were performed with autogenous bone, Bio-Oss or by the association of the two materials. It is important to emphasize that no implant was submitted to immediate loading, and the period of osseointegration for the installation of the provisional prostheses was awaited. All patients received a prescription of $875 \mathrm{mg}$ of amoxicillin every 12 hours for seven days, starting with two capsules one hour before surgery, and for implant surgery, $1 \mathrm{~g}$ of first-generation cephalosporin was prescribed for prophylaxis.

In addition, the same surgeon, with experience in the field, performed all surgeries. We organized the data in a Microsoft Excel spreadsheet and then submitted it to the Binomial Test for proportions at 5\% significance (BioEstat Program, version 5.0).

\section{RESULTS}

Of the 166 patients undergoing grafts, 155 were women (62.5\%) and 93 men (37.5\%), a statistically significant difference $(p<0.0001)$. The patients' ages ranged from 18 to 78 years, the mean age being 50.42 .

Most of the surgeries were onlay grafts for thickness gain, corresponding to $65.32 \%$ (162 grafts), and $34.68 \%$ (86 grafts) were particulate grafts for maxillary sinus floor elevation $(p<0.0001)$. The most common location of the grafts was the posterior maxilla, which received 121 grafts (48.8\%), a percentage statistically higher than that of grafts performed in other maxillo-mandibular regions $(p<0.01)$. On the other hand, the anterior region of the maxilla received $34.27 \%$ of the grafts, which was statistically higher than the proportion of grafts performed in the mandible $(p<0.0001)$. Among the grafts to the mandible, the amount performed in the posterior region (31 grafts $-12.5 \%$ ) was statistically higher than that performed in the anterior onr (11 grafts $-4.43 \%, p<0.013)$.

However, considering only the location of the 162 onlay grafts, the main site was the anterior maxilla region, with 85 grafts, followed by the posterolateral region (35 grafts) and the posterior mandible region (31 grafts). The region with the fewer onlay grafts was the 


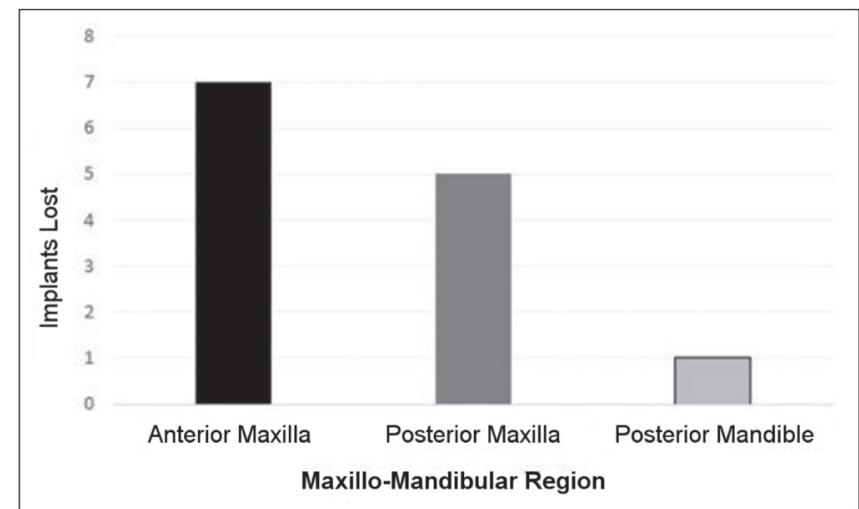

Figure 1. Distribution of lost implants according to the maxillo-mandibular location.

anterior mandible, with 11 . The percentage of grafts performed in the anterior maxillary region (52.47\%) was statistically higher than in all other regions $(p<0.0001)$. Statistical differences were also observed between the proportion of grafts in the posterior region of the maxilla $(21.60 \%)$ compared with the anterior region of the mandible $(6.8 \%, p<0.0001)$, as well as between the posterior (13\%) and anterior (6.8\%) mandible regions $(p<0.0009)$. We found no significant differences in the number of grafts performed between the maxilla and mandible posterior regions $(p<0.5811)$.

In general, most grafts were performed with autogenous bone, corresponding to 219 cases (88.31\%, $\mathrm{p}<0.0001)$. Fourteen cases were done with Bio-Oss (5.64\%) and 15, with the association of Bio-Oss and autogenous bone (6.05\%). When considering only the maxillary sinus regions (86 grafts), the most used material was autogenous bone, in 57 cases (66.28\%).

The 248 grafted areas received 269 implants. Of these, 114 (42.37\%) were inserted in the maxillary sinus area and 155 (57.63\%) in an onlay block area. Of the inserted implants, 256 were osseointegrated (95.17\%) and 13, lost (4.83\%, p<0.0001).

Only 13 implants were installed concurrently with the reconstructive surgeries. Of the implants installed concomitantly to the grafts, only one was lost (8.33\%) and the others were successful (91.67\%). Of the implants installed late, 12 failed (4.68\%) and 244 were osseointegrated (95.32\%). Still in relation to implant losses, ten $(4.51 \%)$ were located in graft sites for gain in thickness (onlay) and only three in areas of maxillary sinus floor elevation (2.63\%). However, there was no statistical difference regarding implant loss according to graft type $(p<0.2424)$.

Regarding the maxillo-mandibular location of the lost implants, only one occurred in the mandible in the posterior region. The others occurred in the maxilla, seven in the anterior region and five in the posterior one. The number of implants lost in the anterior (53.85\%) and posterior (38.46\%) maxilla was statistically higher than in the mandible $(7.69 \%, p<0.0313)$. There was no statistical significance as for implant losses in the maxilla regions $(p<0.4314$, Figure 1).

We observed a greater implants loss in patients over 40 years of age, which corresponded to ten implants lost $(76.92 \%)$. In patients less than 40 years of age, three implant losses $(23.08 \%)$ occurred $(p<0.006)$. Eight implant losses occurred in women and five in men. However, there was no statistical difference between the female (61.54\%) and male (38.46\%) genders ( $p<0,2393)$.

As for graft loss, five were in the maxillary sinus region $(33.33 \%)$ and ten in onlay grafts $(66.67 \%)$, and there was no statistical difference between the different types of grafts $(p<0.0679)$. Most of the lost grafts were located in the maxilla, six (40\%) in the anterior maxilla and seven $(46.47 \%)$ in the posterior region. In the mandible, one graft loss occurred in the anterior region and one in the posterior mandible. There was a statistical difference in the loss of grafts in the anterior $(p<0.0309)$ and posterior $(p<0.0132)$ maxilla regions in relation to the mandible (Figure 2).

Eighty percent of cases of lost grafts (12 grafts) occurred in patients over 40 years and $20 \%$ of cases (three grafts) in patients under 40 years. The proportion of graft loss in patients over 40 years was statistically higher than in patients below 40 years $(p<0.001)$.

\section{DISCUSSION}

Dental implants are being increasingly used because of their high success rates. This modality of rehabilitation is currently considered the most predictable and scientifically accepted treatment for partially or 


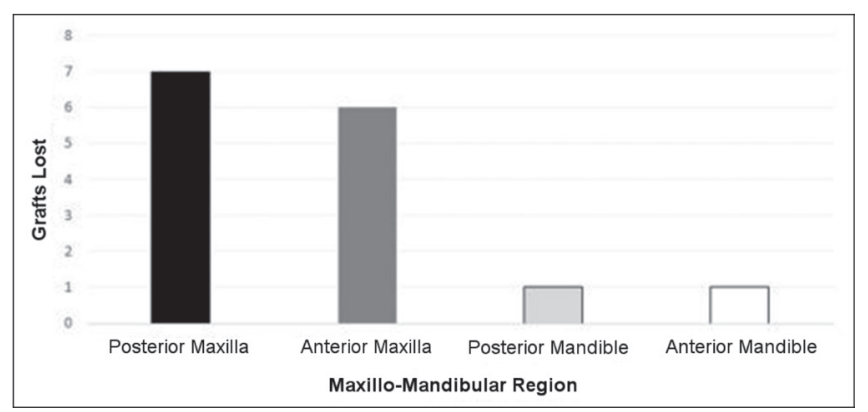

Figure 2. Distribution of lost grafts according to the maxillo-mandibular location.

totally edentulous patients. However, a large proportion of patients do not present sufficient bone conditions for implants installation, thus requiring previous reconstructive bone surgeries ${ }^{5,16}$. In this study, 269 implants were inserted in 248 grafted maxillo-mandibular regions, which displayed a success rate of $95.17 \%$, with only 13 implants lost (4.83\%). In 1986, Branemark and Albrektsson ${ }^{17}$ evaluated implants inserted during a year for a five-year follow-up period and found a high success rate, $96.5 \%$. However, in the systematic review of Albrektsson and Donos ${ }^{18}$, based on 23 retrospective studies with 1312 implants followed during a five-year period, the authors found a higher success rate, which corresponded to $97.7 \%$.

It is important to emphasize that the implants inserted in the present study were followed for a period ranging from four months to 19 years, depending on the time at which they were installed (1995 to 2014). According to Misch ${ }^{10}$, the osseointegration of implants in grafted areas depends on the resulting bone quality. Thus, implants inserted into areas of denser bone tissue may require about two months for osseointegration, whereas in areas of less dense spongy bone tissue it may take up to four months for the same process to occur ${ }^{10}$. Based on this assumption, in this study we included only implants that had a minimum period of four months of follow-up, enough time to evaluate osseointegration even in regions of low bone quality.

Regarding implants loss in the grafted regions, there were no statistically significant differences in the number of implants lost in the onlay graft areas (4.51\%) in relation to maxillary graft ones $(2.63 \%, p<0.2424)$. Cabezas-Monjón et al. ${ }^{3}$ carried out a meta-analysis with the objective of reviewing the success rates of implants inserted in areas of maxillary sinus elevation surgeries over a 10-year period. They observed that of the 3975 implants inserted, 3794 implants were successful, representing a success rate of $94.3 \%$. In the present study, the success rate of implants in maxillary sinus area was higher, corresponding to $97.37 \%$. However, there were no statistical differences regarding the implants success as for graft area (95.49\%, $p<0.2424)$. Another study that indicates a high success rate of implants inserted in areas of maxillary sinus grafted with autogenous bone, in this case of extrabuccal donor area, is that of Sakka and Krenkel ${ }^{9}$. The authors report a success rate of $94.8 \%$. In contrast, in relation to the success of implants in onlay graft areas, in the systematic review by Clementini et al. ${ }^{2}$, they observed a success rate of implants in areas of autogenous graft, which ranged from $72.8 \%$ to $97 \%$, in most of the reviewed studies. Thus, the authors point out that the technique of autogenous onlay grafting is a reliable and predictable technique to obtain the bone volume required for the implant installation ${ }^{2}$. In the work of Kamal et al. ${ }^{5}$, in turn, of the 379 implants inserted in areas reconstructed with autogenous bone, 15 failed (3.95\%), successful implants corresponding to $96.05 \%$.

Regarding the maxillo-mandibular location of the lost implants, more implants were lost in the anterior (53.85\%) and posterior (38.46\%) maxilla, which was statistically significant in relation to mandibular failure (7.69\%, p<0.0313). This may have occurred because, among the situations that increase implant failures, the insertion of maxillary implants stands out, mainly in the posterior region, since it is an area of known low bone quality (type III and IV) ${ }^{19}$. So much so that, according to Chrcanovic et al. ${ }^{19}$, most studies show a higher rate of failure of maxillary implants, with statistical differences in relation to the mandible as observed in the present study. On the other hand, other studies, like the one of Alissa and Oliver ${ }^{16}$, did not find statistical difference in the failure of implants between the maxilla and mandible.

In addition, higher rates of implant failure have been reported in systemically compromised patients ${ }^{16,19}$. In the present sample, all patients were healthy without 
metabolic disturbances, which may also have contributed to the low rate of implant failure (4.83\%). Another factor poorly investigated in the literature that may play a role in the success of dental implants is the use of prophylactic and postoperative antibiotic therapy. Alissa and Oliver ${ }^{16}$ found a significant statistical difference between the success of implants in patients who used antibiotics in the postoperative period and the rates of patients who did not. In the present study, all patients underwent antibiotic therapy, with the use of pre and postoperative amoxicillin for graft surgeries and first-generation cephalosporin prophylactically for implant surgeries.

For the implant inserted in a grafted area to be successful, it is indispensable that the previously performed graft reaches the expected objectives regarding the correction of bone deficiencies. Thus, the success of a bone graft is evaluated for its potential to withstand the tensions and mechanical deformations to which it is submitted. In this way, successful grafts are those that undergo revascularization and replacement by host bone after insertion into the recipient bed, without significant loss of volume and mechanical resistance ${ }^{20}$. In the present study, 248 grafts were performed, between surgeries for gain in thickness (onlay - 65.32\%) and maxillary sinus floor elevation (34.68\%), with a loss rate of only $6.04 \%$. Most of the grafts were performed in the posterior maxilla region $(48.8 \%)$, with statistical difference in relation to the number of grafts performed in the other maxillomandibular regions $(p<0.01)$. It is important to note that implants inserted into grafted areas have a success rate that may be lower, ranging from 60 to $100 \%$. It is speculated that the graft itself may constitute a risk factor for implant success ${ }^{20}$. However, in the present study, all implants were inserted into grafted areas and we do not believe in a negative graft interference in results, since there was a success rate of $95.17 \%$. Carr et al. ${ }^{21}$, in turn, report that the risk of implant failure is five times greater in areas of grafted maxillary sinus compared with the implants installed in residual bone.

Despite this, similar to the results of the present study, Alissa and Oliver ${ }^{16}$ did not identify negative graft interference in implants' osseointegration. These same authors point out that this may have occurred because they opted for the two-stage approach, i.e. implants were only inserted after a minimum period of three months, which allowed graft maturation, obtaining initial implant stability and placement of the implant in a more adequate position ${ }^{16}$. Regarding the moment of implant installation, in the present study, only $4.83 \%$ of the implants were installed concomitantly with the graft. Of these, only one implant (8.33\%) was lost and $91.67 \%$ were successful. However, in the study by Cabezas-Monjón et al. ${ }^{3}$, the success rate of implants installed concomitantly to the graft was slightly higher, corresponding to $94 \%$. However, according to Del Fabbro et $a{ }^{20}{ }^{20}$, there are no significant differences in the success rate of implants, independent of the installation protocol, simultaneous or late. With regard to implants installed late, we had a success rate of $95.32 \%$, which was similar to the rate reported in other studies $(96.8 \%)^{3}$. According to Misch ${ }^{10}$, placement of the implants after the healing period should be preferred. Nevertheless, it is important to install the implants as soon as possible to stimulate the formation and maintenance of bone tissue. In the case of autogenous grafts, a minimum period of four months should be expected ${ }^{10}$. Despite this, due to the small failure rate of implants inserted concomitant to the graft (8.33\%) in the present study, we do not believe that the simultaneous installation of graft and implant had a negative effect on results. Similarly, other authors have evaluated the success of implants inserted concomitantly with maxillary sinus surgeries for a period of 12 to 60 months and observed a high success rate $(98.8 \%)^{8}$. On the other hand, previous studies reported high failure rates, between 25 and $30 \%$, when the implants were inserted simultaneously to the reconstruction of atrophic maxillae with autogenous iliac crest bone 22,23 .

The number of implants (76.92\%) and grafts lost $(80 \%)$ in patients over 40 years was statistically higher than the failures in younger patients $(p<0.001)$. However, the majority of studies found no significant correlations between implant loss and patient age ${ }^{16,19}$. However, as in the present study, Zinser et al. ${ }^{24}$ found a significant interference of age in implant loss. Regarding gender, in 
the present study the majority of lost implants (61.54\%) and grafts $(60 \%)$ occurred in women, though with no significant statistical difference $(p<0.2733)$. This finding is in agreement with the literature, since a great part of the studies do not indicate significant differences between men and women with regard to the implant loss ${ }^{16,19}$.

As for the origin of the materials used in the present study, all 162 onlay grafts were performed with autogenous bone. Similarly, most sinus elevation grafts (66.28\%) were also performed with autogenous bone, and a small percentage of cases were performed with Bio-Oss (16.28\%) or with Bio-Oss and autogenous bone combined $(17.44 \%)$. In the survey of maxillary sinus elevation surgeries of Cabezas-Monjón et al. ${ }^{3}$, most procedures were also performed with autogenous bone (59\%), followed by the use of the association of autogenous bone with a bone substitute $(24 \%)$, Isolated use of bone substitute (10\%), and in $7 \%$ of cases the graft material used was not specified. The authors also report that $18 \%$ of the autogenous bone used was collected from the extraoral area. In contrast, in the present study, $100 \%$ of the autogenous graft was removed from intraocular donor areas. The percentage success of implants inserted in autogenous bone (94.40\%) in the present study was higher than the overall implant survival rate of the Cabezas-Monjón et al. study $(93 \%)^{3}$.

In addition, in the present study, no implant installed in areas of Bio-Oss or Bio-Oss associated with autogenous bone was lost. Although the autogenous graft is considered the "gold standard" in reconstructive bone surgeries due to its osteogenic, osteoconductive and osteoinductive characteristics, in the present study, the highest rate of implant loss was observed in areas grafted with autogenous bone. This can be explained in part by the greater resorption of the material, which in the areas of the maxillary sinus can allow subsequent peneumatization?. In the systematic review of the literature by Jensen et al. ${ }^{7}$, only one study was found that evaluated the survival of implants inserted in areas grafted with Bio-Oss alone (80\%) or Bio-Oss associated with autogenous bone (20\%). Although the highest success rate was observed in the Bio-Oss group (96\%), there was no statistical difference in relation to the group where
Bio-Oss was associated with autogenous bone (94\%). On the other hand, Del Fabbro et al. ${ }^{20}$ found a success rate of implants in sinus lift areas performed exclusively with the bone substitute $(96.1 \%)$ considerably higher than with the use of autogenous bone alone (88.9\%).

Regarding the location of the onlay grafts, in the present study the largest amount of grafts was located in the anterior region of maxilla $(52.47 \%)$, with statistical difference in relation to the other maxillo-mandibular regions. This is understandable, since after a tooth loss, a marked buccal bone resorption occurs in the maxilla, which can lead to loss of up to $50 \%$ of the ridge width, leading to the need for reconstructive surgeries to gain thickness. In addition, the upper anterior region is the aesthetic area of the patient and great efforts therefore are required in bone reconstruction so that the implant is in a position that favors aesthetics. The reconstructions of this region can be especially delicate when the patient presents with a high smile line ${ }^{10}$.

In this context, based on what has been discussed, it is important to identify the factors related to implant failure in regions where bone reconstruction was performed. Failures may be related to local or systemic factors $^{15}$. In the present study, the factors most involved in implant and graft loss were local, since patients were healthy. Despite this, age had a significant influence on implant loss. Given this caveat, the authors believe that the implant losses of the present sample may be related to the vascularization, density and resorption of the bone tissue obtained after the reconstructions. This is because the quality of obtained bone tissue can interfere with the primary stability and osseointegration process, as pointed out by Sjöström et al. ${ }^{15}$. Primary stability, in turn, is an important aspect for the consolidation of osseointegration and can be affected by bone quality, surgeon skill and surgical technique ${ }^{15}$. Based on the assumption that in the present study all surgeries were performed by the same experienced surgeon, who used an accurate surgical technique, we do not believe that technical aspects have interfered with the implants' results. Moreover, another important aspect in assessing the success of implants is immediate loading. Most studies show higher failure 
rates found in early loaded implants ${ }^{15}$. Nonetheless, in this study all implants were loaded late after the period of osseointegration. Thus, immediate loading was not a predictive factor of implant failure in the studied sample.
In the sample studied, there were few cases of graft and implant failure. Reconstructive and implant surgeries performed in the maxilla and in patients over 40 years showed a higher rate of failure.

\title{
R E S U M O
}

\begin{abstract}
Objetivo: investigar os fatores preditivos de falhas em enxertos ósseos para aumento do rebordo alveolar e cirurgia de implantes. Métodos: os prontuários de 166 pacientes, operados entre 1995 e 2014, foram revistos. Um total de 248 enxertos foi realizado. Os dados foram submetidos ao teste binomial a $5 \%$ de significância. Resultados: os enxertos para ganho em espessura do rebordo alveolar $(65,32 \%)$ foram mais frequentes do que levantamentos de seio maxilar $(p<0,0001)$ e o número de enxertos para a região posterior da maxila $(48,8 \%)$ foi maior do que em outras regiões $(p<0,01)$. Foram perdidos $6,04 \%$ dos enxertos. As perdas em maxila anterior $(p<0,0132)$ e posterior $(p<0,0309)$ foram maiores do que na mandíbula. Foram instalados 269 implantes nas áreas enxertadas e apenas $4,83 \%$ perdidos. O número de implantes perdidos (4,51\%) em áreas de enxertos em bloco não foi estatisticamente maior do que na área de seios maxilares enxertados $(2,63 \%)(p<0,2424)$. As perdas foram maiores na região anterior $(53,85 \%)$ e posterior $(38,46 \%)$ da maxila em relação a mandíbula $(p<0,031)$ e, $76,92 \%$ dos enxertos $(p<0,006)$ e $80 \%$ dos implantes perdidos $(p<0,001)$, foram instalados em pacientes com mais de 40 anos de idade. Conclusão: maior taxa de falhas foi observada para enxertos e implantes dentários realizados em maxila e em pacientes com mais de 40 anos de idade.
\end{abstract}

Descritores: Regeneração óssea. Transplante Ósseo. Implantes Dentários.

\section{REFERENCES}

1. Parithimarkalaignan S, Padmanabhan TV. Osseointegration: an update. J Indian Prosthodont Soc. 2013;13(1):2-6.

2. Clementini M, Marlupi A, Agrestini C, Ottria L. Success rate of dental implants inserted in autologous bone graft regenerated areas: a systematic review. Oral Implantol. 2011;4(3-4):3-10.

3. Cabezas-Monjón J, Barona-Dorado C, Gómez-Moreno G, Fernández-Cáliz F, Martínez-González JM. Meta-analytic study of implants survival following sinus augmentation. Med Oral Patol Oral Cir Bucal. 2012;17(1):e135-9.

4. Esposito M, Felice P, Worthington HV. Interventions for replacing missing teeth: augmentation procedures of the maxillary sinus. Cochrane Database Syst Rev. 2014;13(5):CD008397.

5. Kamal D, Abida S, Jammet P, Goudot P, Yachouh J. Outcome of oral implants after autogenous bone reconstruction. Rev Stomatol Chir Maxillofac. 2009;110(2):86-8.

6. Herford AS, Dean JS. Complications in bone grafting. Oral Maxillofac Surg Clin North Am. 2011;23(3):433-42.

7. Jensen T, Schou S, Stavropoulos A, Terheyden H, Holmstrup P. Maxillary sinus floor augmentation with
Bio-Oss or Bio-Oss mixed with autogenous bone as graft: a systematic review. Clin Oral Implants Res. 2012;23(3):263-73.

8. Johansson L, Isaksson S, Lindh C, Becktor JP, Sennerby L. Maxillary sinus floor augmentation and simultaneous implant placement using locally harvested autogenous bone chips and bone debris: a prospective clinical study. J Oral Maxillofac Surg. 2010;68(4):837-44.

9. Sakka $S$, Krenkel C. Simultaneous maxillary sinus lifting and implant placement with autogenous parietal bone graft: outcome of 17 cases. J Craniomaxillofac Surg. 2011;39(3):187-91.

10. Misch CM. Maxillary autogenous bone grafting. Oral Maxillofac Surg Clin North Am. 2011;23(2):229-38.

11. Ronden RD Jr. Principles of bone grafting. Oral Maxillofac Surg Clin North Am. 2010;22(3):295-300.

12. Louis PJ. Bone grafting the mandible. Dent Clin North Am. 2011;55(4):673-95.

13. Misch K, Wang HL. Implant surgery complications: etiology and treatment. Implant Dent. 2008;17(2):159-68.

14. Winkler S. Extraordinary implant failure. J Oral Implantol. 2010;36(5):391-400.

15. Sjöström M, Sennerby L, Lundgren S. Bone graft healing in reconstruction of maxillary atrophy. Clin Implant Dent Relat Res. 2013;15(3):367-79. 
16. Alissa R, Oliver RJ. Influence of prognostic risk indicators on osseointegrated dental implants failure: a matched case-control analysis. J Oral Implantol. 2012;38(1):52-61.

17. Branemark PI, Albrektsson T. Endosteal dental implants in the treatment of the edentulous jaw. The Branemark implant. In: Fonseca RJ, Davis WH, editors. Reconstructive Preprosthetic Oral and Maxillofacial Surgery. Philadelphia: WB Saunders; 1986. p.210-24.

18. Albrektsson T, Donos N; Working Group 1. Implant survival and complications. The Third EAO consensus conference 2012. Clin Oral Implants Res. 2012;23 Suppl 6:63-5.

19. Chrcanovic BR, Albrektsson T, Wennerberg A. Reasons for failure of oral implants. J Oral Rehabil. 2014;41(6):443-76.

20. Del Fabbro M, Rosano G, Taschieri S. Implant survival rates after maxillary sinus augmentation. Eur J Oral Sci. 2008;116(6):497-506.

21. Carr AB, Choi YG, Eckert SE, Desjardins RP. Retrospective cohort study of the clinical performance of 1-stage dental implants. Int J Oral Maxillofac Implants. 2003;18(3):399-405.
22. Adell $\mathrm{R}$, Eriksson $\mathrm{B}$, Lekholm $\mathrm{U}$, Brånemark PI, Jemt T. Long-term follow-up study of osseointegrated implants in the treatment of totally edentulous jaws. Int J Oral Maxillofac Implants. 1990;5(4):347-59.

23. Isaksson S. Evaluation of three bone grafting techniques for severely resorbed maxillae in conjunction with immediate endosseous implants. Int J Oral Maxillofac Implants. 1994;9(6):679-88.

24. Zinser MJ, Randelzhofer P, Kuiper L, Zöller JE, De Lange GL. The predictors of implant failure after maxillary sinus floor augmentation and reconstruction: a retrospective study of 1045 consecutive implants. Oral Sur Oral Med Oral Pathol Oral Radiol. 2013;115(5):571-82.

Received in: 09/11/2016

Accepted for publication: 06/12/2016

Conflict of interest: none.

Source of funding: none.

\section{Mailing address:}

Marina Reis Oliveira

E-mail: marinareis89@hotmail.com drfued@icloud.com 